\title{
La Educación en las constituciones de los países del Cono Sur americano
}

\author{
Vicente Llorent-Bedmar ${ }^{a}$ \\ Mercedes Llorent-Vaquero ${ }^{b}$
}

\section{Resumen}

La constitución de cada Estado define el régimen básico de los derechos y libertades de sus ciudadanos, a la vez que rige la organización y el desarrollo del mismo régimen, articulando su propio sistema de convivencia, y configurándose como la guía reguladora de normas sociales, familiares y educativas. Las constituciones rigen dos de los ámbitos más importantes para la transformación/consolidación de nuestras sociedades: el familiar y el educativo. Las constituciones de los países estudiados -Argentina, Chile, Paraguay y Uruguay- no sólo reconocen el alto valor que la familia representa para el Estado y la sociedad, sino que además la favorecen y protegen. Establecen los derechos básicos de las familias y, al mismo tiempo, imponen al propio Estado obligaciones que acaban beneficiándolas. Desde un punto de vista teleológico observamos cómo, en todas ellas, a través de la educación, se pretende el desarrollo de la personalidad humana, haciendo especial hincapié en los aspectos morales.

Palabras-clave: Constitución. Educación. Familia. Cono Sur.

\section{Introducción}

La desigualdad distributiva que campa por el mundo en el que vivimos emerge de forma innegable en el sur de América. Esta indeseable inequidad dificulta la constitución de sociedades equitativas e integradas. Además, la desigualdad que se da en el ámbito de las oportunidades educativas, en función del nivel socioeconómico de los estudiantes, es algo realmente considerable. Así, la educación tampoco es capaz de romper el círculo vicioso de pobreza y desigualdad

\footnotetext{
a Universidad de Sevilla - Facultad de Ciencias de la Educación, Teoria y Historia de la Educación y Pedagogia Social. Sevilla, Espanã.

b Universidad de Sevilla - Facultad de Ciencias de la Educación - Departamento de Didáctica y Organización Educativa. Sevilla, España.
} 
social, todavía más acuciante cuando observamos las diferencias entre los ámbitos rurales y urbanos (BLANCO; CUSATO, 2011, p. 3). La equidad y la cohesión social se muestran como dos grandes desafíos político-educativos con los que se enfrentan las sociedades de Argentina, Chile, Paraguay y Uruguay, cuyos países fueron objeto de nuestro estudio. El marco constitucional que subyace a las legislaciones desarrolladas en dichos países tiene una indudable importancia. De ahí nuestro interés por estudiar las referencias que, en sus respectivas Cartas Magnas, se hacen en las materias de familia y educación.

Ante la indefensión a la que se hallaban sometidos los seres humanos, en las sociedades premodernas, estos se fueron aglutinando en torno a la familia, la tribu y las pequeñas comunidades, como una garantía para su supervivencia. Con la llegada de la modernidad su situación cambia profundamente. Mientras que en los ámbitos rurales la familia continuaba protegiendo a sus miembros autoabasteciéndoles en sus necesidades, no podemos decir que ocurriese lo mismo en las ciudades, donde la indefensión de las personas aumentaba ante innúmeros avatares. Así, los altos niveles de interdependencia de la ciudad, un entorno mucho más amplio que el rural, propiciaban que el individuo y su familia se abrieran a otros niveles de relación. De esta manera surge una corriente ideológica que reivindica un Estado benefactor, un Estado que proteja personas y familias de la nueva y vulnerable situación que se vive en las ciudades (CONTRERAS, 1996), abanderando así la lucha en pro de los derechos sociales. Con el objetivo de paliar buena parte de estos problemas, las modernas Constituciones incluyen una serie de garantías donde el estado se hace responsable del individuo y de la familia, otorgándoles unos derechos a ambos y asumiendo su defensa.

A nivel nacional nos encontramos con la Carta Magna o ley fundamental de cada Estado, donde se define el régimen básico de los derechos y libertades de los ciudadanos, así como de los poderes e instituciones de la organización política, que no es otra que la Constitución política (en adelante, Constitución). Esta norma jurídica suprema positiva, que rige la organización y el desarrollo de un Estado, constituye el marco referencial que, desde el inicio de la modernidad, utilizan los habitantes de cada Estado para articular su propio sistema de convivencia ${ }^{1}$. Este esencial pilar, sobre el que se desarrolla la vida de los ciudadanos, tiene como fin "[...] el equilibrio entre el poder de los gobernantes y los derechos de los gobernados, fijando límites y controles a los primeros y regulando los derechos y obligaciones de los segundos [...]” (MACHICADO, 2010, p. 15), y

\footnotetext{
${ }^{1}$ Aristóteles ya nos decía que "La constitución no es otra cosa que la repartición regular del poder" (Aristóteles: Política, Libro VI, capítulo III).
} 
se conforma en la guía reguladora de normas sociales, familiares y educativas. Como sea que toda legislación de un país democrático se desarrolla en un marco legal marcado por su Carta Constitucional, se nos hace sumamente interesante estudiar detenidamente cómo se contemplan, en dichas Constituciones, los ámbitos familiar y educativo, tan importantes para la trasformación/consolidación de nuestra sociedad, epicentro de nuestro estudio.

En los albores del s. XX, con la Constitución Política de Estado de Querétaro Arteaga (México), en 1917, se inauguró el reconocimiento de los derechos sociales en las Constituciones. En Europa, la primera Constitución que se refiere a la protección de la familia por parte del Estado fue la denominada Constitución de Weimar de 1919 (CARMONA, 2000), en sus artículos 23 y 50 (GIRALDO, 2002). Aunque, realmente fue con la Ley Fundamental de Bon en 1949 cuando el Estado social de derecho adquirió reconocimiento constitucional.

Tras la instauración de un proceso formal de alternancia institucional en Paraguay, que se inició con el fin del gobierno del general Alfredo Stroessner, y de un proceso de transición desde las dictaduras militares a regímenes electorales en Argentina, Chile, Uruguay y Bolivia, en toda América Latina, con excepción de Cuba, se instauraron regímenes políticos democráticos. Así, en la década de los ochenta se puso fin a los regímenes autoritarios de Argentina, Uruguay y Paraguay, mientras que Chile tuvo que esperar al año de 1990. Con el cambio de régimen, el ejercicio del poder público dejó de estar en manos de gobernantes de facto para ser ejercido por presidentes y parlamentos democráticamente elegidos, a través de comicios libres y pluralistas. Tal es así, que el acceso al poder público a través de las urnas se ha vuelto una rutina constitucional en los mencionados países.

\section{Regulación general de la educación}

La organización federal existente en la República de Argentina va acompañada de un complejo ordenamiento jurídico, que es imprescindible conocer para poder comprender el sistema educativo de este país. La Constitución Nacional establece que "[...] cada provincia dictará para sí una constitución bajo el sistema representativo y republicano [...] que asegure [...] la educación primaria [...]”. Del mismo modo, atribuye al Congreso Nacional el "proveer lo conducente a la prosperidad del país, al adelanto y bienestar de las provincias y al progreso de la ilustración, dictando planes de instrucción general y universitaria..." (ARGENTINA, 1994, en línea). 
En Argentina, será el Congreso quien sancionará leyes de organización y de base de la educación que consoliden la unidad nacional respetando las particularidades provinciales y locales, de modo que aseguren la responsabilidad indelegable del Estado, la participación de la familia y la sociedad, la promoción de los valores democráticos y la igualdad de oportunidades y posibilidades sin discriminación alguna; y que garanticen los principios de gratuidad y equidad de la educación pública estatal y la autonomía y autarquía de las universidades nacionales (ARGENTINA, 1994, Art. 75.19).

Los fundamentos básicos del sistema educativo de Chile están consagrados esencialmente en la Constitución Política de la República ${ }^{2}$. En ella se mencionan los conceptos fundamentales y los principios de organización y gestión del sistema educativo, desarrollados con la nueva Ley General de Educación $n^{\circ} 20.370$, promulgada el 17 de agosto de $2009^{3}$. Ésta representa el marco para una nueva institucionalidad de la educación en el país, en lo referente a educación básica y media, manteniéndose la normativa anterior respecto a la educación superior.

El texto sistematizado de la Constitución Política de Chile, aprobada en 1980 y reformada en 2003, fue promulgado mediante el Decreto $\mathrm{n}^{\circ} 100$ de 17 de septiembre de 2005. La modificación constitucional de 2003 se realizó mediante la Ley ${ }^{\circ}$ 19.876 con la intención de asegurar 12 años de escolaridad obligatoria y gratuita para todos los jóvenes chilenos hasta los 21 años de edad.

Provee de un marco para la descentralización del sistema escolar y para la desconcentración del Ministerio de Educación (CHILE, 1980, Art. 3).

Se prevé que una Ley Orgánica Constitucional establezca los requisitos mínimos en cada uno de los niveles de enseñanza básica y media, y señale las normas objetivas, de general aplicación, que permitan al Estado velar por su cumplimiento. Dicha ley establecerá los requisitos para el reconocimiento oficial de los establecimientos educacionales de todo nivel (CHILE, 1980, Art. 19.11).

En Paraguay, la organización del sistema educativo es responsabilidad esencial del Estado, con la participación de las distintas comunidades educativas; el sistema abarca los sectores públicos y privados, así como los ámbitos escolar y extraescolar (PARAGUAY, 1992, Art. 76). Por otro lado, en la misma Constitución se afirma

\footnotetext{
2 Aprobada en 1980 y modificada en 2003 mediante la Ley n 19.876.

3 Esta nueva ley ha derogado la anterior Ley Orgánica Constitucional de Enseñanza dictada en 1900 y sus posteriores modificaciones.
} 
que la educación es responsabilidad de la sociedad y recae particularmente en la familia, en el Municipio y en el Estado (PARAGUAY, 1992, Art. 75).

La educación en Uruguay está basada en principios plasmados en la Constitución de la República y en la normativa legal vigente. Ambas recogen los principios básicos: libertad de pensamiento, de enseñanza y de cátedra; así como la laicidad, obligatoriedad, gratuidad y autonomía de la enseñanza con respecto al poder ejecutivo.

En nuestro inicial análisis de los principios establecidos en la Constitución uruguaya en materia educativa, hemos detectado tres aspectos que estimamos de esencial importancia: A. Uruguay es un estado laico (URUGUAY, 1967, Arts. 5, 54 y 58). B. La familia es la base de la sociedad (URUGUAY, 1967, Art. 40). C. El cuidado y la educación de los hijos es un deber y un derecho de los padres (URUGUAY, 1967, Art. 41).

Un principio constitucional que caracteriza el sistema educativo de Uruguay es el de autonomía técnica y administrativa de los Entes de Enseñanza (Entes Autónomos ${ }^{4}$ ) respecto al Poder Ejecutivo. La Enseñanza Pública Superior, Secundaria, Primaria, Normal, Industrial y Artística, serán regidas (administradas) por uno o más Consejos Directivos Autónomos (URUGUAY, 1967, Art. 202). Éstos sólo pueden tener los cometidos relativos a la enseñanza, o sea, impartir la enseñanza pública y ejercer el control de la enseñanza privada (URUGUAY, 1967, Arts. 202-205). No existe un control discrecional del Poder Ejecutivo sobre los Entes Autónomos de la Enseñanza cuando se considere inconveniente o ilegal la gestión de los Consejos Directivos (URUGUAY, 1967, Art. 205).

Corresponden al Intendente las funciones ejecutivas y administrativas en el Gobierno Departamental (URUGUAY, 1967, Art. 274). Entre sus atribuciones se encuentra: velar por la salud pública y la instrucción primaria, secundaria y preparatoria, industrial y artística, proponiendo a las autoridades competentes los medios adecuados para su mejoramiento (URUGUAY, 1967, Art. 275).

\subsection{Familia y educación}

El primordial y básico papel otorgado a las familias en las Constituciones analizadas, así como la responsabilidad de los padres en la educación de sus hijos,

\footnotetext{
${ }^{4}$ La creación de Entes Autónomos está prevista en los artículos 189 Inc. 1, 202 Inc. $1^{\circ}$ y 205 de la Constitución.
} 
Tabla 1 - El papel de las familias en la educación de sus hijas e hijos

\begin{tabular}{|c|c|}
\hline Argentina & $\begin{array}{l}\text { "la ley establecerá: [...] la protección integral de la familia; la defensa del bien } \\
\text { de familia; la compensación económica familiar y el acceso a una vivienda } \\
\text { digna" (Art. } 14 \text { bis). } \\
\text { "[...] el Senado sancionará leyes de organización y de base de la educación que } \\
\text { consoliden la unidad nacional respetando las particularidades provinciales y } \\
\text { locales: que aseguren la responsabilidad indelegable del Estado, la participación } \\
\text { de la familia y la sociedad" (Art. 75.19). }\end{array}$ \\
\hline Chile & $\begin{array}{l}\text { "La familia es el núcleo fundamental de la sociedad" (Art. 1). } \\
\text { "Es deber del Estado [...] dar protección a la población y a la familia, propender } \\
\text { al fortalecimiento de ésta [...]" (Art. 1). } \\
\text { "Los padres tienen el derecho preferente y el deber de educar a sus hijos. Cor- } \\
\text { responderá al Estado otorgar especial protección al ejercicio de este derecho" } \\
\text { (Art. 19.10). } \\
\text { "Los padres tienen el derecho de escoger el establecimiento de enseñanza para } \\
\text { sus hijos" (Art. 19.11). }\end{array}$ \\
\hline Paraguay & $\begin{array}{l}\text { "La familia es el fundamento de la sociedad. Se promoverá y se garantizará su } \\
\text { protección integral. Esta incluye a la unión estable del hombre y de la mujer, a } \\
\text { los hijos y a la comunidad que se constituya con cualquiera de sus progenitores } \\
\text { y sus descendientes" (Art. 49). } \\
\text { "Los padres tienen el derecho y la obligación de asistir, de alimentar, de educar } \\
\text { y de amparar a sus hijos menores de edad" (Art. 53). } \\
\text { "La familia, la sociedad y el Estado tienen la obligación de garantizar al niño } \\
\text { su desarrollo armónico e integral, así como el ejercicio pleno de sus derechos" } \\
\text { (Art. 54). } \\
\text { "La educación es responsabilidad de la sociedad y recae en particular en la } \\
\text { familia, en el Municipio y en el Estado" (Art. 75). }\end{array}$ \\
\hline Uruguay & $\begin{array}{l}\text { "La familia es la base de nuestra sociedad. El Estado velará por su estabilidad } \\
\text { moral y material, para la mejor formación de los hijos dentro de la sociedad" } \\
\text { (Art. 40). } \\
\text { "El cuidado y educación de los hijos para que estos alcancen su plena capaci- } \\
\text { dad corporal, intelectual y social, es un deber y un derecho de los padres" (Art. } \\
41 \text { ) } \\
\text { "Los padres tienen para con los hijos habidos fuera del matrimonio los mismos } \\
\text { deberes que respecto a los nacidos en él. La maternidad, cualquiera sea la } \\
\text { condición o estado de la mujer, tiene derecho a la protección de la sociedad y a } \\
\text { su asistencia en caso de desamparo" (At. 42). }\end{array}$ \\
\hline
\end{tabular}

Fuente: Argentina (1994), Chile (1980), Paraguay (1992) y Uruguay (1967).

queda patente con meridiana claridad, con una salvedad: en el caso de Argentina su Constitución se refiere explícitamente a las familias y no a los padres. Todo ello queda de manifiesto en la Tabla 1:

\subsection{Fines de la educación}

En Argentina, corresponde al Congreso sancionar leyes de organización y de base de la educación que consoliden la unidad nacional respetando las particularidades provinciales y locales; que aseguren la responsabilidad indelegable del Estado, la 
participación de la familia y la sociedad, la promoción de los valores democráticos y la igualdad de oportunidades; y que garanticen los principios de gratuidad y equidad de la educación pública estatal así como la autonomía y autarquía de las universidades nacionales (ARGENTINA, 1994, Art. 75.19).

A partir del marco establecido por el artículo 4 de la Constitución de Chile, donde se señala que este país es una república democrática, diversos textos enuncian jurídicamente las finalidades de la educación chilena.

1. El artículo 19.10 de la propia Constitución Política, estipula que la educación tiene por objeto el pleno desarrollo de la persona en todas las etapas de su vida.

2. La Ley Orgánica Constitucional de Enseñanza desarrolla el citado precepto Constitucional entendiendo la educación como un proceso permanente que abarca las distintas etapas de la vida de las personas y que tiene como finalidad alcanzar su desarrollo moral, intelectual, artístico, espiritual y físico. Para conseguirlo propone que se realice mediante la trasmisión y el cultivo de valores, conocimientos y destrezas, de modo que los capacite para convivir y participar de forma responsable y activa en la comunidad (CHILE, 2009, Art. 2). Tras reconocer la existencia de las modalidades de educación formal e informal, indica las finalidades de los grandes ciclos de enseñanza formal, la básica (CHILE, 2009: Art. 19) y la media (CHILE, 2009, Art. 20).

En la Constitución de Paraguay se indica que la finalidad de la educación estriba en el desarrollo pleno de la personalidad humana, así como en la promoción de la libertad, la paz, la justicia social, la solidaridad, la cooperación y la integración de los pueblos; el respeto a los derechos humanos y los principios democráticos; la afirmación del compromiso con la Patria, de la identidad cultural y la formación intelectual, moral y cívica, así como la eliminación de los contenidos educativos de carácter discriminatorio (PARAGUAY, 1992, Art. 73). Mientras que la finalidad principal de las universidades y de los institutos superiores será la formación profesional superior, la investigación científica y la tecnológica, así como la extensión universitaria (PARAGUAY, 1992, Art. 79).

En la Constitución de Uruguay se indica con claridad que la utilidad social, que ha de orientar los contenidos educativos, requiere una mención especial. Hace hincapié en que todas las instituciones docentes han de atender especialmente a la formación del carácter moral y cívico de los alumnos (URUGUAY, 1967, Art. 71). 
Tabla 2 - Derecho a la educación

\begin{tabular}{ll}
\hline Argentina & $\begin{array}{l}\text { "Todos los habitantes de la Nación gozan de los siguientes derechos conforme } \\
\text { a las leyes que reglamenten su ejercicio [...] de enseñar y aprender" (Art. 14). }\end{array}$ \\
\hline Chile & "La Constitución asegura a todas las personas: [...] el derecho a la educación" \\
& (Art. 19.10). \\
\hline Paraguay & "Toda persona tiene derecho a recibir una educación integral y permanente, \\
& $\begin{array}{l}\text { que como sistema y proceso se realiza en el contexto de la cultura de la comu- } \\
\text { nidad" (Art. 73). }\end{array}$ \\
\hline Uruguay & "El Estado velará por su estabilidad moral y material, para la mejor formación \\
& de los hijos dentro de la sociedad" (Art. 40).
\end{tabular}

Fuente: Argentina (1994), Chile (1980), Paraguay (1992) y Uruguay (1967).

\subsection{Derecho a la Educación}

Aunque en todas las Constituciones de los países analizados se consagra el derecho a la educación (Tabla 2), en dos de ellos se hace de forma pormenorizada:

1. La Constitución de Chile asegura el derecho a la educación de todas las personas (CHILE, 1980, Art. 19), especificando que ésta tiene por objeto el pleno desarrollo de la persona en las distintas etapas de la vida. Incluso observamos como al Estado le corresponde promover la educación de párvulos ${ }^{5}$. En el mismo precepto se formula el principio de la obligatoriedad de la educación básica y se encarga al Estado la financiación de un sistema gratuito, con el objetivo de asegurar el acceso de toda la población a las enseñanzas básica y media (CHILE, 1980: Art. 19.10). En el caso de la educación media, este sistema se extenderá hasta que el alumnado cumpla los 21 años de edad ${ }^{6}$.

2. En la Constitución de Paraguay observamos cómo se diferencia el derecho a la educación y sus fines, previstos en su artículo 73, del derecho de aprender y la libertad de enseñar, desarrollado en su artículo 74. En efecto, en el primero se estipula que toda persona tiene derecho a una educación integral y permanente, que como sistema y proceso se realiza en el contexto de la cultura de la comunidad. Mientras que en el segundo se garantizan el derecho de aprender y la igualdad de oportunidades para acceder a los beneficios derivados de la cultura humanística, de la ciencia y de la tecnología, sin discriminación alguna. Igualmente se garantiza la libertad de enseñar, sin más requisitos que la idoneidad y la integridad ética, así como el derecho a la educación religiosa y al pluralismo ideológico.

\footnotetext{
${ }^{5}$ Modificado por Ley 19.634 de 1999.

${ }^{6}$ Inciso sustituido por el artículo único de la ley de Reforma Constitucional № 19.876.
} 
Los derechos sociales fundamentales de la Constitución de Paraguay tienen, en su mayoría, una pretensión de universalidad, dado que ellos están concebidos como derechos para todas las personas sin distinción alguna. Además, se consignan obligaciones constitucionales que de una forma explícita implican un apoyo estatal para aquellos colectivos de personas más vulnerables. En este sentido, observamos cómo se hace alusión a determinados objetivos específicos de la acción estatal, entre los que se encuentran: las mujeres que son cabeza de familia (PARAGUAY, 1992:Art. 53), las personas excepcionales (PARAGUAY, 1992: Art. 58), niños en edad escolar provenientes de familias de escasos recursos (PARAGUAY, 1992, Art. 75) y la mujer campesina (Art. 115.9). Además, se dispone que el Estado establecerá las condiciones necesarias para que los grupos de menos recursos se vean favorecidos por determinadas políticas sociales, tales como la distribución de fondos para becas y ayudas a la educación (PARAGUAY, 1992, Art. 80), la construcción y adjudicación de viviendas de interés social (PARAGUAY, 1992, Art. 100).

\subsection{Gratuidad y obligatoriedad escolar}

El derecho a la educación está íntimamente unido a la gratuidad y obligatoriedad escolar. Al respecto, podemos observar en la Tabla 3 la coherencia de las Constituciones analizadas:

Tabla 3 - Gratuidad y obligatoriedad escolar

\begin{tabular}{ll}
\hline Argentina & "Corresponde al congreso [...] sancionar leyes de organización y de base de \\
& la educación [...] que garanticen los principios de gratuidad y equidad de la \\
& educación pública estatal y la autonomía y autarquía de las universidades \\
& nacionales" (Art. 75.19). \\
& "Cada provincia dictará para sí una Constitución [...] que asegure [...] la edu- \\
& cación primaria" (Art. 5). \\
\hline Chile & "Financiar un sistema gratuito con tal objeto, destinado a asegurar el acceso a \\
& ella de toda la población" (Art. 19.10). \\
\hline Paraguay & "La educación escolar básica es obligatoria. En las escuelas públicas tendrá \\
& carácter gratuito. La organización del sistema educativo es responsabilidad \\
& esencial del Estado, con la participación de las distintas comunidades educati- \\
& vas. Este sistema abarcará a los sectores públicos y privados, así como al ámbito \\
& escolar y extraescolar" (art. 76). \\
\hline "Son obligatorias la enseñanza primaria y la enseñanza media, agraria o indus- \\
trial" (Art. 70). \\
"Declárase de utilidad social la gratuidad de la enseñanza oficial Primaria, \\
Media, Superior, Industrial y Artística y la Educación Física; la creación de \\
becas de perfeccionamiento y especialización cultural, científica y obrera, y el \\
establecimiento de bibliotecas populares" ( Art. 71).
\end{tabular}

Fuente: Argentina (1994), Chile (1980), Paraguay (1992) y Uruguay (1967). 


\subsection{Igualdad/no discriminación}

Aunque en las Constituciones estudiadas se reconoce la igualdad de todos los ciudadanos ante la ley - como quedará patente en la Tabla 4 -, es igualmente cierto que, en dos de estas Constituciones, a los pueblos indígenas se les dedican artículos de gran interés con la finalidad de defender sus peculiaridades:

1. En Argentina se reconoce la preexistencia étnica y cultural de los pueblos indígenas, garantizando el respeto a su identidad y el derecho a una educación bilingüe e intercultural (ARGENTINA, 1994, Art. 75.17). Siguiendo la Ley de Educación Nacional de 2006, la educación intercultural bilingüe constituye una modalidad del sistema educativo argentino en sus niveles de educación inicial, primaria y secundaria. Con ella se garantiza el derecho constitucional de los pueblos indígenas a recibir una educación que contribuya a preservar y fortalecer sus pautas culturales, su lengua, su cosmovisión e identidad étnica, a desempeñarse activamente en un mundo multicultural y a mejorar su calidad de vida (Ley $n^{\circ} 26.206,2006$, Art. 52).

2. Respecto a Paraguay, dadas sus especiales características demográficas, en su Constitución se prevé que el Estado respete las peculiaridades culturales de los pueblos indígenas, especialmente en lo relativo a la

Tabla 4 - Igualdad y no discriminación

\begin{tabular}{ll}
\hline Argentina & "Corresponde al congreso [...] legislar y promover medidas de acción positiva \\
& que garanticen la igualdad real de oportunidades y de trato" (Art. 75.23). \\
& "Corresponde al congreso [...] sancionar leyes de organización y de base de la \\
& educación que [...] aseguren [...] la igualdad de oportunidades y posibilidades sin \\
& discriminación alguna" (Art. 75.19). \\
& "Corresponde al Congreso [...] dictar leyes que protejan la identidad y plurali- \\
& dad cultural, la libre creación y circulación de las obras del autor; el patrimonio \\
& artístico y los espacios culturales y audiovisuales" (Art. 75.19).
\end{tabular}

Fuente: Argentina (1994), Chile (1980), Paraguay (1992) y Uruguay (1967). 
educación formal. Atendiendo, además, a su defensa contra la regresión demográfica, la depredación de su hábitat, la contaminación ambiental, la explotación económica y la alienación cultural (PARAGUAY, 1992, Art. 66).

\subsection{Libertad de enseñanza}

Desde una concepción del hombre que exige la libertad de cultura y de pensamiento, en estas Constituciones, se propicia la libertad de enseñanza, y con ella el derecho de enseñar y de aprender. Esta libertad, garantizada en cada Constitución (Tabla 5), constituye uno de los cimientos básicos del Estado.

Aunque en todas las Constituciones analizadas se hace expresa alusión a la religión, observamos como en la de Argentina se especifica que el Gobierno Federal ha de sostener el culto católico apostólico romano (ARGENTINA, 1994, Art. 2). En contraste con la de Uruguay, donde se proclama la libertad de cultos religiosos (URUGUAY, 1967, Art. 5); o la de Chile, donde se defiende taxativamente la libertad de conciencia y el ejercicio libre de todos los cultos que no se opongan a la moral, a las buenas costumbres o al orden público (CHILE, 1980, Art. 19.6). En el ámbito educativo, la Constitución de Paraguay da un paso más, pues, al igual que en la de Argentina, reconoce el protagonismo de la Iglesia Católica en la

Tabla 5 - La libertad de enseñanza como derecho constitucional

\begin{tabular}{ll}
\hline Argentina & "Asegurar los beneficios de la libertad, para nosotros, para nuestra posteridad, \\
& y para todos los hombres del mundo que quieran habitar en el suelo argen- \\
& tino" (Preámbulo). \\
& Todos los habitantes de la Nación gozan de los siguientes derechos [...] de \\
& enseñar y aprender" (Art. 14). \\
& Los consumidores y usuarios de bienes y servicios tienen derecho [...] a la liber- \\
& tad de elección (Art. 42). \\
\hline Chile & "La libertad de enseñanza incluye el derecho de abrir, organizar y mantener \\
& establecimientos educacionales. La libertad de enseñanza no tiene otras limita- \\
& ciones que las impuestas por la moral, las buenas costumbres, el orden público \\
& y la seguridad nacional" (Art. 19.11). \\
& "Se reconoce a los padres "el derecho de escoger el establecimiento de ense- \\
& ñanza para sus hijos" (Art. 19.11). \\
& "La Constitución asegura a todas las personas la libertad de enseñanza, inclui- \\
& do el derecho de abrir, organizar y mantener centros educativos" (Art. 19.11). \\
\hline "Se garantiza igualmente la libertad de enseñar, sin más requisitos que la & idoneidad y la integridad ética" (Art. 74). \\
\hline Paraguay & "Queda garantizada la libertad de enseñanza" (Art. 68). \\
& La libertad de pensamiento y de cátedra quedan garantizadas (Art. 29). \\
\hline Uruguay &
\end{tabular}

Fuente: Argentina (1994), Chile (1980), Paraguay (1992) y Uruguay (1967). 
formación histórica y cultural de la Nación (PARAGUAY, 1992, Art. 82), afirmando el derecho a la educación religiosa y al pluralismo ideológico (PARAGUAY, 1992, Art. 74).

\subsection{Investigación científica}

En Argentina, corresponde al Congreso proveer el desarrollo humano, el progreso económico con justicia social, la productividad de la economía nacional, la generación de empleo, la formación profesional de los trabajadores, así como la investigación y desarrollo científico y tecnológico, su difusión y aprovechamiento (ARGENTINA, 1994, Art. 75.19).

Mientras que en Chile, el Estado se responsabiliza del fomento de la educación en todos sus niveles, del estímulo de la investigación científica y tecnológica, la creación artística, y de la protección e incremento del patrimonio cultural de la Nación (CHILE, 1980, Art. 19.10), añadiendo que es deber de la comunidad contribuir al desarrollo y perfeccionamiento de la educación.

Igualmente, al Estado de Paraguay le corresponde fomentar la enseñanza media, técnica, agropecuaria, industrial y superior, así como la investigación científica y tecnológica (PARAGUAY, 1992, Art. 76). Aún más; la Constitución se detiene a indicar como los recursos destinados a la educación en el presupuesto general de la nación no podrán ser inferiores al veinte por ciento del total asignado a la Administración Central, excluidos los préstamos y las donaciones (PARAGUAY, 1992, Art. 85).

Respecto a la educación técnica, esta Constitución indica que el Estado ha de fomentar la capacitación para el trabajo por medio de la enseñanza técnica, a fin de formar los recursos humanos requeridos para el desarrollo nacional (PARAGUAY, 1992, Art. 78). Dedicándole un artículo a las universidades e institutos superiores, donde se señala que su finalidad principal estriba en la formación profesional superior, la investigación científica y la tecnológica, así como en la extensión universitaria. Las universidades disfrutarán de autonomía y establecerán sus propios estatutos, formas de gobierno y planes de estudio de acuerdo con su política educativa y sus planes de desarrollo nacional. Las universidades, tanto públicas como privadas, serán creadas por ley, la cual determinará las profesiones que necesiten títulos universitarios para su ejercicio. Garantizándose, en ambas, la libertad de enseñanza y de cátedra (PARAGUAY, 1992, Art. 79). Por último, se garantizan el derecho a aprender y la igualdad de oportunidades para el acceso 
a los beneficios de la cultura humanística, de la ciencia y de la tecnología, sin discriminación alguna (PARAGUAY, 1992, Art. 74).

De una forma clara y escueta, en la Constitución de Uruguay se precisa que corresponde al Estado el desarrollo de la investigación científica y de la enseñanza técnica (URUGUAY, 1967, Art. 70).

\section{Conclusiones}

La educación se nos muestra como una imposición de la sociedad, que desea alcanzar, a través de la misma, el saber, los conocimientos, las tecnologías, la ciencia, e incluso la filosofía. Por tanto, la educación constituye un valioso instrumento para el desarrollo de las personas y de la sociedad de un determinado país. Del mismo modo, la sociedad necesita de la educación para su desarrollo y el control de sus miembros.

Por tanto, el estudio de la educación en cada país tiene que partir, ineludiblemente, de las cláusulas constitucionales que condicionan su legislación educativa, y que muestran las pretensiones del Estado, como entidad de poder.

Constatamos la frecuencia con que aparecen los aspectos educativos en la parte programática de las constituciones, aunque algunos textos constitucionales se refieran a ellos como derecho básico y prerrogativa del ciudadano. No obstante, generalmente se pueden localizar en las cláusulas constitucionales programáticas, con lo que se pone de manifiesto el interés que las Constituciones estudiadas muestran sobre los aspectos educativos, al referirse a ellos de forma clara y contundente.

Las Constituciones de todos los países estudiados no sólo reconocen el alto valor que la familia representa para el Estado y la sociedad, sino que además la favorecen y protegen, tanto directa como indirectamente. No sólo establecen los derechos básicos de las familias, sino que a su vez imponen al propio Estado obligaciones que redundan en su beneficio. Sin lugar a dudas, la institución familiar ha sido objeto de una especial preocupación por parte de los creadores de las Constituciones analizadas, y, por supuesto, el ámbito educativo ha sido un aspecto cuidado de forma explícita.

Los padres de la Constitución de los países estudiados se preocuparon de impedir que el Estado asumiera la patria potestad o tutela de los menores, concediendo 
a los padres este derecho y deber sobre sus hijos, en tanto menores de edad. Así pues, prevalece el derecho y el deber de los padres para encaminar a sus hijos hacia la educación que estimen más oportuna. En las mencionadas Constituciones se considera a la familia como núcleo fundamental de la sociedad, sobre el cual se basará la educación de los menores. El Estado, como garante de la educación, es el responsable último del sistema educativo. Las Constituciones pretenden reglamentar la enseñanza estatal, colocando al Estado al frente del proceso educacional y aceptando el valor complementario del sector privado. Uruguay es el país donde los Entes de Enseñanza adquieren mayor relevancia.

De una forma explícita, como en las Constituciones de Argentina, Chile y Paraguay, o de forma implícita, como en la Constitución de Uruguay, se prevé que todas las personas tengan derecho a la educación. En todas ellas se cita expresamente la gratuidad de la enseñanza pública. Del mismo modo, se garantizan de forma inequívoca la igualdad de oportunidades y la no discriminación. Así pues, observamos como todos los ciudadanos tienen los mismos derechos constitucionales, especialmente los de enseñar y aprender.

Respecto a la equidad y cohesión social incluimos la ilustrativa Tabla 6 que nos aclara con meridiana claridad algunos aspectos sociales relativos a los países estudiados:

En consonancia con la exministra de Planificación de Chile, Clarisa Hardy, estimamos que, en América Latina, las desigualdades sociolaborales persisten y favorecen la continuidad de unos sistemas educativos segmentados que, a su vez, segregan a la población. Aún más, estas brechas distributivas se ven agravadas por las condiciones de género, edad y ruralidad. A pesar de haberse universalizado la educación primaria en toda América Latina, persisten algunas dificultades de escolaridad en la educación secundaria, y, sobre todo, en la

Tabla 6 - Estratificación social en los países estudiados

\begin{tabular}{lcccc}
\hline & Argentina & Chile & Paraguay & Uruguay \\
\hline Estratos extrema pobreza & 4,2 & 2,9 & 18,4 & 2,6 \\
\hline Estratos pobreza moderada & 6,6 & 7 & 14,3 & 5,4 \\
\hline Total estratos pobres & 10,8 & 9,9 & 32,8 & 29 \\
\hline Estratos vulnerables & 31,4 & 40,5 & 40,5 & 47,7 \\
\hline Estratos medios con seguridad económica & 54,4 & 44 & 25,5 & 23,1 \\
\hline Estratos altos & 3,4 & 5,6 & 1,3 & 0,2 \\
\hline
\end{tabular}

Fuente: Hardy (2014). 
educación inicial o preescolar, por no hablar de las carencias en la educación superior.

Desde un punto de vista teleológico observamos, en las cuatro Constituciones, como, a través de la educación, se pretende el desarrollo de la personalidad humana, haciendo especial hincapié en los aspectos morales.

En todas ellas se hace expresa alusión a la salud del individuo como un derecho fundamental, buscando su promoción; así como se habla de la protección del medio ambiente.

Las libertades también se tienen en cuenta; especialmente la libertad de enseñanza que queda plasmada inequívocamente en todas las Constituciones. Entre las libertades que se defienden está la libertad de culto, que, a su vez, propicia una enseñanza religiosa. Siguiendo esta línea, se detecta claramente la preocupación constitucional por defender la enseñanza pública, sin menoscabo de la educación privada. Destaca el especial énfasis que en Argentina se pone a favor de la religión católica.

El fomento de la investigación científica se halla fuertemente presente en las cuatro Constituciones analizadas. Sin embargo, respecto al desarrollo tecnológico, observamos que no ocurre del mismo modo. Mientras que en la mayoría de ellas se hace explícita alusión al tema, como sucede en los casos de Argentina (Art. 75.19), Chile (Art. 19.10) o Paraguay (Arts. 74, 76 y 79), llama la atención la ausencia de referencias sobre la enseñanza tecnológica en la constitución de Uruguay, si bien dichas referencias existen respecto a la enseñanza técnica (Art. 70).

Con mayor o menor fuerza, las universidades son citadas en todos los textos constitucionales. En todas ellas, de una manera implícita y muy fuerte, constatamos una interesantísima dialéctica. Por un lado nos encontramos con una autonomía universitaria, la llamada libertad de cátedra y la inviolabilidad del recinto universitario, tendentes a defender las libertades educativas e investigadoras. Mientras que, por otro lado, constatamos la presencia de un poder público, antaño influido por un catolicismo autoritario y, hoy en día por una tendencia estatalizante.

En las citadas Constituciones se reconoce la igualdad de todos los ciudadanos ante la ley. Aún más; dos de dichas Constituciones apoyan explícitamente 
los derechos de los pueblos indígenas, defendiendo sus peculiaridades. En Argentina se reconoce la preexistencia étnica y cultural de los pueblos indígenas, garantizando el respeto a su identidad y el derecho a una educación bilingüe e intercultural. En Paraguay se alude expresamente al pueblo guaraní, para que el Estado respete las peculiaridades culturales de los pueblos indígenas, especialmente en lo relativo a la educación formal.

\section{Referencias}

ARGENTINA. Constitución de la Nación Argentina 22 de agosto de 1994. 1994. Disponível em: <http://www.libertadreligiosa.net/legislacion/Constitucion_ Argentina.pdf $>$. Acesso em: 23 nov. 2013.

BLANCO, R.; CUSATO, S. Desigualdades educativas en América Latina: todos somos responsables. 2011. Disponível em: <http://www.buenastareas. com/ensayos/Desigualdades-Educativas-De-America-Latina/1821672.html>. Acesso em: 8 mar. 2013.

CARMONA, E. El Estado Social de Derecho en la Constitución. Madrid: Consejo Económico y Social, 2000.

CHILE. Constitución Política de la República de Chile de 1980. Santiago de Chile, 1980. Texto actualizado al 1 de octubre de 2005. Disponível em: $<\mathrm{http}: / /$ www.gob.cl/media/2010/05/Constituci\%C3\%B3n-de-Chile1.pdf>. Acesso em: 14 nov. 2013.

. Ley $n^{\circ}$ 20.370. Ley General de Educación. Santiago de Chile, 2009. Disponível em: $<$ http://www.leychile.cl/Navegar?idNorma=1006043>. Acesso em: 15 nov. 2013.

CONTRERAS, F. J. Defensa del Estado Social. Sevilla: Servicio de Publicaciones de la Universidad de Sevilla, 1996.

GIRALDO, J. A. Constitución y familia. 2002. Disponível em: < derecho.udea. edu.co/descargas/Flia1/7_jasael_giraldo.pdf $>$. Acesso em: 7 agosto 2014.

HARDY, C. Retos de cohesión social en América Latina. Asunción: CADEP, 2014. 
MACHICADO, J. La Constitución Política del Estado . Apuntes Jurídicos, 2010. Disponível em: <ermoquisbert.tripod.com/pdfs/cpe.pdf>. Acesso em: 4 dez. 2013.

PARAGUAY. Constitución de la República del Paraguay del 20 de junio de 1992. Disponível em: <http://www.gparlamentario.org/spip/IMG/pdf/Constitucion Nacional_de_20-6-1992___Paraguay.pdf $>$. Acceso em: 29 nov. 2013.

URUGUAY. Constitución de la República Oriental del Uruguay DE 1967, con las modificaciones plebiscitadas el 26 de noviembre de 1989, el 26 de noviembre de 1994, el 8 de diciembre de 1996 y el 31 de octubre de 2004. Disponível em: $<$ http://www.parlamento.gub.uy/constituciones/const004.htm>. Acesso em: 6 nov. 2013.

\section{A Educação nas constituições dos países do Cone Sul americano}

\section{Resumo}

A Constituição da cada Estado define o regime básico dos direitos e liberdades dos cidadãos, ao mesmo tempo em que rege a organização e o desenvolvimento do mesmo, articulando seu próprio sistema de convivência e se conformando na guia reguladora de normas sociais, familiares e educativas. As Constituições regem dois âmbitos tão importantes para a transformação/consolidação de nossas sociedades: o familiar e o educativo. As Constituições dos países estudados - Argentina, Chile, Paraguai e Uruguai - não só reconhecem o alto valor que a familia representa para o Estado e a sociedade, como também a favorecem e protegem. Estabelecem os direitos básicos das famílias, ao mesmo tempo em que impõem ao próprio Estado obrigações que as beneficiam. De um ponto de vista teleológico, observamos como, em todas as Constituições, através da educação, pretende-se o desenvolvimento da personalidade humana, fazendo especial finca-pé em aspectos morais.

Palavras-chave: Constituição. Educação. Família. Cone Sul. 


\section{Education in the constitutions of the American Southern Cone countries Abstract}

The constitution of every State defines the basic regime of the rights and freedoms of citizens, and simultaneously rules their organization and development, articulating their own system of acquaintanceship and conforming in the regulatory guide of social, familiar and educational norms. Constitutions govern two very important areas for the transformation/consolidation of society: family and education. The constitutions of the studied countries - Argentina, Chile, Paraguay and Uruguay - not only recognize the high value of the family for the State and society, but also favor and protect it. They establish the basic rights of families while impose obligations on the State to benefit them. From a teleological point of view, we observe how all of them, through education, claim the development of human personality, with special support to moral aspects.

Keywords: Constitution. Education. Family. Southern Cone.

\section{Informações dos autores}

Vicente Llorent Bedmar: Doutorado em Curso de Doctorado Educación y Sociedad. Contato: 1lorent@us.es

Mercedes Llorent Vaquero: Máster en Dirección, Evaluación y Calidad de las Instituciones de Formación. Contato: mllorent@us.es 